Print ISSN: 2053-5821(Print), Online ISSN: 2053-583X (Online)

\title{
FACTORS AFFECTING B2C BUYERS BEHAVIOUR OF E-COMMERCE INDUSTRY IN THE CONTEXT OF BANGLADESH
}

\author{
Mohammad Wahidul Islam \\ Lecturer; School of Business Administration; East Delta University \\ Muhammad Asif Imtiaz \\ East Delta University
}

\section{Samia Binte Hamid}

\begin{abstract}
E-Commerce is rapidly growing as an impressive manifestation of globalization. The rapid expansion of e-commerce is a major opportunity for local and international trade in Bangladesh. The amount of trade conducted electronically has grown dramatically with the penetration of smart phones and internet among all segments of population in Bangladesh. Consumers prefer to shop online for various reasons such as saving time, better prices, convenience, higher selection options, and availability of products \& services. Thus the businesses are required to understand the consumers' expectations, attitudes, and behaviour across the globe. Among the e-commerce variety, B2C (Business to Consumer) model is the most prominent. The purpose of this study is to examine the factors which affect consumers buying behaviour. The study addresses the cultural differences, risk perceptions, and attitude by investigating Bangladeshi people about using B2C e-commerce sites, by analysing content of website, privacy and security, ethics in website, and motivation as an independent variable. The data is collected through online survey with 130 participants (119 usable), with the criteria that they purchase or order some product or service in online web sites in Bangladesh. The results show that B2C websites somewhat reflects the cultural impact that surrounds the consumer decision making. Individuals are also concerned with the data privacy and security. The paper also discusses some critical factors needed to successfully run an e-commerce start-up.
\end{abstract}

KEYWORDS: B2C, e-commerce, buying behaviour, start-up

\section{BACKGROUND OF THE STUDY}

Separating time and space fences is useful for both businesses and consumers in e-commerce. E-commerce provides a number of benefits for the business organization like high accessibility, innovative, interoperability, interactivity and information. In terms for the consumers, ecommerce produces more information that reaches in less time and provides facility for purchasing (Ratnasingam, 2005). It appears that the nature of information technology and the acceptances of e-commerce require a change in the business process that can bring about a change in the culture. Various studies have tried to evaluate the success and failure of ecommerce. Because the e-commerce market is made up of different people and cultures, which has different views on trust. Obviously, every culture has its own history, language, religion, 
and identity that have been affected by completely different experiences (Changchit, Garofolo, $\&$ Gonzalez, 2009). People from different cultures will see different aspects of e-commerce as more or less useful as traditional shopping. Building a trust in e-commerce for more culturally, users requires friendly web interface features (Cyr \& Fraser, 2004). Therefore, the intention of the buyer who purchase online will get support through cultural factors development ecommerce websites (Singh, Zhao, \& Hu, 2012). In recent years, research interests in the cultural aspects of B2C e-commerce web site have increased significantly. Culture has been acknowledged as an important factor for online consumer behaviour. For a $\mathrm{B} 2 \mathrm{C}$ e-commerce website to successfully conduct business worldwide, presentation of website features should be delivered through cultural factors such as localization to attract their local customers (Sun, 2010). The purpose of this research to investigate is that consumer understanding of the online culture and what drive consumer to use purchase through e-commerce website. Not every ecommerce site sees that success some of them face hush reality and fail to meet customer expectation. The research tries to understand why consumers are visiting or purchasing from those sites and if not, why. This study has attempted to discover which factors mainly influence consumers to buy from e-commerce and the managerial implications of the same.

\section{LITERATURE REVIEW}

\section{E-Commerce in Bangladesh}

Bangladesh is developing country and here e-commerce still in developing stage even though it started in 1990s (e-Commerce Association of Bangladesh, 2019). At that time only number of non-resident Bangladeshi posted books and gift through e-commerce in capital city Dhaka. By 2001-2008 it gained a much greater space even with lack to knowledge and infrastructure. In 2012 e-commerce market change in Bangladesh when Akhoni and Ajkerdeal come to existing to online consumer. This gave a boost for investment in e-commerce and entry of the business entrepreneur not only from Bangladesh but from abroad as well. Amazon, Alibaba (who bought Daraz.com.bd), Walmart, joined the competition along with the numerous local companies operating in this space (Dhaka Tribune 1,2019) (Dhaka Tribune 2, 2019). The total market size of B2C E-Commerce in Bangladesh is approx. BDT 900 crore as per multiple sources and expected to grow significantly in the next few years. (Brain Station 23, 2019) (New Age, 2019). In 2018 IDLC monthly review suggests that the e-commerce in Bangladesh has growth rate of $19.4 \%$ average annual growth since 2012. (IDLC, 2018). With innovative solutions like Deligram, aggressive strategies by Daraz, Pikaboo etc. this would be an interesting space to watch.

\section{Business to-Consumer (B2C) E-Commerce in Bangladesh}

Business-to-Consumer (B2C) e-commerce is involved between the businesses and the consumers. Most of B2C e-commerce deals with purchasing of physical goods like books or any consumer product, information goods like software, e-book, games, song etc., and personal finance management like e-banking. A report from the e-Cab tells those E-commerce mass users are from. Dhaka, Chittagong, and Gazipur with up to $80 \%$ users are from these cities. $35 \%$ traffic is from Dhaka which is the highest, 29\% Chittagong, and 15\% Gazipur respectively. The other cities also showing promising growths The reaction is quite 
invigorating, "Customers from rural areas are also purchasing huge volumes of products, which is a new phenomenon for this kind of business" a former president of e-Cab Razib Ahmed said to the news agency (e-Commerce Association of Bangladesh, 2019). Bangladesh has a huge potential for participation in the global market through e-commerce but there is some lagging which through country behind from its competitor in the global market, mainly in B2C dimension (Mohiuddin, 2014). A start-up, very popular term in current business scope, refers to a firm early in their life cycle, started typically by 2-3 persons, to solve a problem whose solution is not obvious, and success is not guaranteed by any means (Robehmed, 2013) (McGowan, 2018). It is estimated by Techinasia that there are total 280 start-ups (mainly software firms and e-commerce ventures) currently operating in Bangladesh. These start-ups are predominantly located in Dhaka city and huge market is unexplored in other parts of the country (Toru Institute of Inclusive Innovation, 2019) (Imran, 2019). A note of advice for these star-ups will be to avoid the common reasons of failure; namely not understanding customer needs properly, wrong business model etc. (Yohn, 2019) (Skok, 2019) (Arnaud, 2018).

\section{Factors in B2C E-Commerce}

Internet has great impact on the people because it can assist billions of users all over the continents. Thousands of local and global networks including private, public, academic, business, and government networks, all provide to the making of the. In research of culture aspect in business to customer e-commerce researcher found various factor involve such as security and privacy, consumer resources, age, lifestyle, attitude, motivation, personality, values, communication and writing style, language option, navigation models, ethics, gender, public policy, advertisement, awareness, human interaction, procedural compatibility, corporate structure, and prior e-commerce (Akhter, 2016); all these factor have their influence in buying decision drive from the local culture (Al-Hamar, Dawson, \& Guan, 2010). Some of the studies on the impact of cross-cultural have unveiled major variance among cultures in in buying decision when it comes on online platform. A cross-cultural validation study of an internet consumer trust model (Jarvenpaa, Tractinsky, \& Vitale, 2000). There is some affirmation of cross-cultural differences it is unclear whether it might be cross-cultural variables or key (Sialaa, O'Keefeb, \& Hone, 2000) (Simon, 2000). Now a days taste, preference and choices are depending on different factors such as the internet emergence, this progress requires more understanding about customer behaviour to make purchasing decision that used outline process has finds that a genera model of buying behaviour.

The $\mathrm{B} 2 \mathrm{C}$ e-commerce website is the medium, and the message form is marked by the cognitive and responsive responses of the buyer by depicting cultural content in the B2C e-commerce (Singh, Zhao, \& Hu, 2012) (Singh, Kumar, \& Baack, 2005), who presented a unique way to measure cultural values on websites that present cultural structures. It is important for countries economic development to embrace the culture of e-commerce (Flood, 2014) (Belkhamza \& Wafa, 2014). The show the world and to compete in global market, the local culture can make impact on the designing of the e-commerce site (Lin, 2015). The cultural differences are evident only in customers with no previous e-commerce experience but are also invisible to consumers with prior e-business experience (Sun, 2010). Park et al. (2012) propose that cultural values impact how consumers with Eastern and Western backgrounds form trust in ecommerce. Chen et al. (2008) explore trust development among virtual community members 
in China, Hong Kong and Taiwan, and find no significant differences in trust development across the countries but show that overall Chinese show a higher trust tendency. Effective B2C e-commerce website such as visual delightful, accessible content information and consumers' faith will be easy to navigate and put in to consumers from different cultures. The B2C model is conducted directly between company and consumers via a website. In the B2C model, businesses or organizations trade goods or services to customers over the internet for consumers' own use. They developed a framework for the dimensions of the ranking trust and to examine their impact on attitudes in the new and familiar business to users in business to consumer e-commerce environment. One of the important aspects that can lead to business successful is the language used in e-commerce website. Using customer's language is benefiting for the e-commerce site when it come on selling. It also indicates that the number of visitors is increase four time higher than the average visitor, when site is using local language (Dan, 2014).

Another notable topic in the study was the kind of advertisements shown on e-commerce websites. One culture advertisement may not suitable for another culture when it come from international trader. Advertisement for e-commerce few things have been observed that due to low cost and accessibility to different product in site it's become most owing plat-form for purchasing items as Internet become a great place for online advertisement to gain and attract consumer's (Rowley, 2001). "In the Internet environment, consumers do not need to conform to the expectations of others when making a purchase, and they all have informational influence that enables them to make good decisions". Advertisements on internet give a strong tool that used to market products and services by the industrial and non-industrial organizations. Banners, pop ups, videos, content and other advertisement links are new form of advertisement for e-commerce (Manchanda, 2006)

The study from Wang, et al., (2009), show another factor is that privacy and security data of customer create concern when using online site for business. For the customer the company's policies need to be in simply the use of data so that they can understand the intention use of data or whether the customer can restrict the use of personal information where user know that all companies are not giving fully guarantee for the security. "Non-expert users will not fully comprehend the scope of the technological measures on a website but will react to the perceived strength of a website's security." (Smith, 2004). User must feel that their personal data, including financial details will not be abused (Lauer \& Deng, 2007).

On the basis of the discussion above, the research looks into the different crucial factors of B2C E-Commerce of Bangladesh market with specific focus on Chattogram city.

\section{Methodology}

The study was conducted in Chattogram city and information were collected through a structural questionnaire. The questionnaire was distributed to the target group over internet. Systematic sampling technique was used while selecting the target group total of 130 persons responded to the questionnaire and 119 responses were usable. A five points Likert rating scale of questionnaire from strongly disagree (1) to strongly agree (5) were adopted to measure the variables. In the survey questionnaire, there are 18 direct questions placed. Apart from the 
demographic questions, each of the others items was rated on the five-point Likert scale. The dependent variable in the study was Buying Behavior, whereas the independent variables were Content of Website, Privacy \& security, Ethics in Website and Motivation. The independent variables were measures by specific questions in the questionnaire.

\section{Findings and Analysis}

From the survey data of 119, age group divide into 4 categories and 23-26 are 53\% in survey, $4.5 \%$ data collected from the age group of 27-34 and 35 above are only $3 \%$ of the survey data. In this research which is mostly focusing on students' use of e-commerce, Graduate student are $43 \%, 22.7 \%$ and $33.3 \%$ are from Post Graduate and other respectively. It was found that respondents mostly buy cloths online (57.6\%), followed by Hotel/Travel booking (33.3\%), electronics products $(30.3 \%)$ and $21.2 \%$ buy event tickets. Figure 1 below demonstrates the Purchasing Frequency of products \& services online.

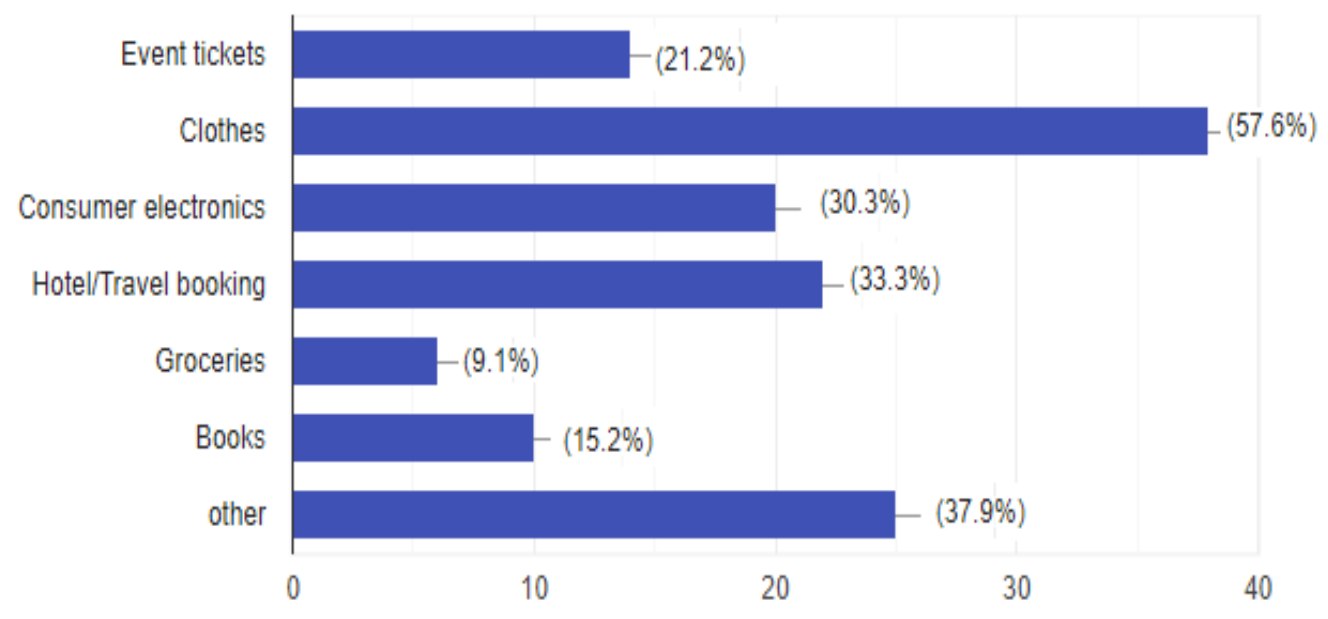

Figure 1 Purchasing Frequency of products \& services online

\section{Reliability Test}

Table 1 Reliability Statistics

\begin{tabular}{|l|l|}
\hline Cronbach's Alpha & N of Items \\
\hline .797 & 17 \\
\hline
\end{tabular}

Cronbach's alpha is one of the most commonly used methods to test the reliability and internal consistency of the test items (Trochim \& Donnelly, 2006). Nunnally \& Bernstein (1994) suggest that if there are two or more subscales in an instrument, Cronbach's alpha should be calculated for the individual subscales, as well as the entire scale as a whole

The Cronbach's alpha is 0.797 ; this confirms the internal consistency and reliability of the model. According to Nunnally (1978) the minimum level of reliability for a model depends on how the model is being used. Lance et al. (2006) suggests that the requirement of having a Cronbach's alpha value above 0.70 for every measurement scale is an urban legend. 


\section{Descriptive Statistics}

Table 2 Descriptive Statistics show Mean Std. Deviation

\begin{tabular}{|l|l|l|l|}
\hline & Mean & Std. Deviation & N \\
\hline Buying Behavior & 3.3950 & 1.12158 & 119 \\
\hline Content of Website & 3.1765 & 1.20484 & 119 \\
\hline Privacy \& Security & 3.1765 & 1.06283 & 119 \\
\hline Ethics in Website & 3.0756 & .97563 & 119 \\
\hline Motivation & 3.4958 & 1.08044 & 119 \\
\hline
\end{tabular}

Table 2 shows that the mean value of buying behavior is 3.3950 with the standard deviation is 1.2158 , content of website and privacy \& security show that its mean value is same at 3.1765 only the standard deviation is slightly differing from each other with 1.20484 and .063238 , ethics in website show that mean value is 3.0756 and the standard deviation is at .97563 , motivation which has highest mean value among all variable with 3.4958. The $\mathrm{N}$ show the total number of respondents who participant in survey where 119.

\section{Regression Analysis}

Table 3 Model Summary

\begin{tabular}{|c|c|c|c|c|c|c|c|c|c|}
\hline \multirow[b]{2}{*}{ Model } & \multirow[b]{2}{*}{$\mathbf{R}$} & \multirow[b]{2}{*}{$\begin{array}{l}\mathbf{R} \\
\text { Square }\end{array}$} & \multirow[b]{2}{*}{$\begin{array}{l}\text { Adjusted } \\
\text { R } \\
\text { Square }\end{array}$} & \multirow{2}{*}{$\begin{array}{l}\text { Std. } \\
\text { Error of } \\
\text { the } \\
\text { Estimate }\end{array}$} & \multicolumn{5}{|c|}{ Change Statistics } \\
\hline & & & & & $\begin{array}{l}\text { R } \\
\text { Square } \\
\text { Change }\end{array}$ & $\begin{array}{l}\text { F } \\
\text { Change }\end{array}$ & df1 & df2 & $\begin{array}{l}\text { Sig. F } \\
\text { Change }\end{array}$ \\
\hline 1 & $.819 a$ & .761 & .728 & 3.04130 & .197 & 5.724 & 4 & 114 & .000 \\
\hline
\end{tabular}

Table 3 shows the Model Summary for the present test. The model fit the output consists of model summary table and ANOVA table. As can be seen the linear regression coefficient $\mathrm{R}=$ 0.819 indicates that there is a strong relationship between the dependent and the independent variable. In terms of variability, the value is $\mathrm{R}=0.761$ or $76.1 \%$, which explains the strength of the population Further use of adjusted $\mathrm{R}^{2}$ leads to a revised estimate that $72.8 \%$ of variability Buying behaviour in the sample which is explained by four independent variables. And the Standard Error of Estimate value reflected in the Table is 3.04130. 
Table 4 ANOVA

\begin{tabular}{|l|l|l|l|l|l|l|}
\hline \multicolumn{2}{|l|}{ Model } & $\begin{array}{l}\text { Sum of } \\
\text { Squares }\end{array}$ & Df & Mean Square & F & Sig. \\
\hline \multirow{2}{*}{1} & Regression & 24.827 & 4 & 6.207 & 5.724 & $.000 \mathrm{~b}$ \\
\cline { 2 - 7 } & Residual & 123.610 & 114 & 1.084 & & \\
\cline { 2 - 6 } & Total & 148.437 & 118 & & & \\
\hline
\end{tabular}

Setting the confidence interval at 95\%, the results of ANOVA test in Table 4 provides an Ftest value for the null hypothesis. Through analysis it accepts the Null hypothesis where $\mathrm{F}=$ 5.724 and $\mathrm{p}=0.000(\mathrm{P}<0.01)$ wherein confidence interval is by default set at $95 \%$ and thus conclude that Motivation, Privacy \& security, Content of Website, Ethics In Website reflect significant relation with Buying Behaviour.

Table 5 Coefficients

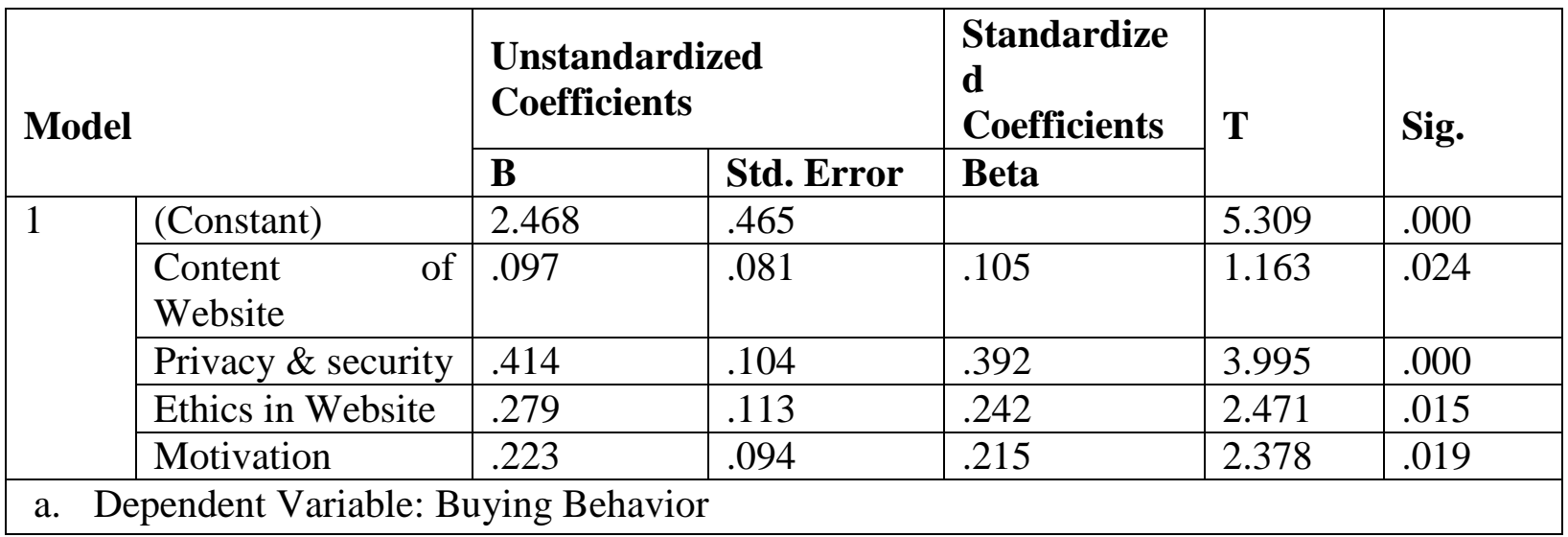

The Coefficient output shown in Table 5, Coefficients provides the estimation of regression coefficients, standard error of estimates, t-tests, and Significance. In order to test the null hypothesis, the t-statistic value where it reflects that content of Website (0.024), Ethics in Website (0.019), Privacy \& security (0.0001), Motivation (0.019) has effect on the Buying Behavior.

\section{DISCUSSION}

The analysis show that model is fit with significant level in under 5\% from that point of view it is understandable that cultural factor does have effect on consumer buying behaviour. Cultural factors that most influence the consumer in the purchase of shopping online. There is a lack of certainty amongst the respondents about the current security measures in place to protect their data and privacy. The majority of individual are varying concern regarding their 
personal data when they are purchasing online. Large number on consumer prefer cash on delivery payment on clothing product but in event and booking ticket consumer are very much concern in security because in this consumer have to share credit card information.

The young and vibrant population of Bangladesh is making the internet business sites increasingly famous. Even, e-commerce sites are breaking the notion that online purchase of electrical items. This significant role of recognition as an extra predecessor of trust has once in a while been accentuated in the internet business setting, however broadly utilized, by the business. This research, featuring the impact of web store nature on trust, gives further help to the little work considering recognition inside the web-based business setting. Security and trust is main tool for making a situation good to online business. "Except if guaranteeing purchaser security, buyer's information assurance and countering cybercrime web-based business division are not satisfying and cannot pull in potential shoppers as found in previous reports" (E-Commerce Association of Bangladesh, 2016) (The Daily Star, 2018) (New Age, 2018). Privacy and security are normal and some protection against such misfortunes is required. Fourthly the customer anticipates some plan of action in the event that they are disappointed with the shopping background. Together these Customer affirmations structure a reduction for customer saw chance.

One of the factors is important in this is content of website which shows that people are prefer more in English language than the Bangla. The research also found that Ali express (Daraz.com), Bagdoom, Booking.com, Pickaboo and Bikroy.com are mostly preferred by the consumers. The online ticketing procedure is exceptionally helpful and efficient for a large portion of the people groups and individuals think that it's extremely advantageous as opposed to fundamental shopping. Customer are genuinely a happy and find the web shopping furthermore attracting and their experiences on electronic shopping was incredible. It's genuinely a not too bad get that the research find that the idea of the things is differentiate from on the web store to separated store. In any case, the examination shows that the web-based learning is additionally. It is certain that conventional advertising and Web showcasing incorporate different highlights by methods for which it is conceivable to impact shopping conduct. As to the way that the present customers are increasingly more impervious to these upgrades, web-based life may speak to the primary heading where it is conceivable to go in the region of online purchaser conduct. Consumers shop directly for the drive needs items to be purchased and the facilities, the quality of goods is guaranteed, so that consumers have more confidence to shop directly. As a creating nation, Bangladesh is still in the progression of its online business. It can expect that sooner rather than later Bangladesh will play a pioneer job in this area.

\section{Managerial Recommendations}

- Meet some early prerequisites to accomplish consumer loyalty. The online shops need to guarantee that whatever the item or administration they are selling, it is immaculate. Online buying customers look for more comfort and development and are fewer brands cognizant. Toward the day's end, consumer loyalty relies upon the nature of the items. 
- Expansion of the item quality is one of the basic targets for customers. E-commerce site should take a few significant measures to make consumer data secure and give a decent consumer experience.

- Customer's Security and Customer experience ought to be the worry of all advertisers. Improving item show in the site. Making mindfulness among shopper and increase their trust by guaranteeing them obtaining on the web is secure. Decreasing item conveyance time by improved strategic group.

- E-commerce is to make sites including components which depend on standards and cultural. It is important for organizations to relate online business arrangements and practices with nearby principles to not be seen as dishonest.

\section{Conclusion, Study Limitations and Scope for the Future Studies}

The present study needs to be refined by future researches working in this area. The study is preliminary, and it provides the groundwork for future studies. Future researchers can incorporate other factors facilitating. This means that future research will be needed to upgrade the present framework as new technological advances make certain web features obsolete or standardized and add new ways of customizing web content. More research is needed to draw with different variable research implications. The research on e-commerce will identify concerns regarding culture and e-commerce on which both the government sector and business organizations should focus to improve and invest. The factors used in the research show that consumers are very careful about the privacy and research when it's come to buying from ecommerce site especially on buying ticket as for buying cloths found that payment on done when they receive the product purchased from the site. The amount of time spent online by people is a key factor to consider regarding the future of e-commerce. Although the set objectives for the research were met, few limitations of the study are worth pointing out. The study was limited to a small sample size in Bangladesh and may not be generalizable for other countries and situations. However, researchers believe the findings are not discounted by the limitations. Additionally, the idea of the research can be adopted in a broader scale within the country among various social groups / segments to understand a more dynamic and behavioural aspects.

\section{References}

Akhter, F. (2016). Cultural Dimensions of Behaviors Towards E-Commerce in a Developing Country Context. International Journal of Advanced Computer Science and Applications, 7(4), 100-103.

Al-Hamar, M., Dawson, R., \& Guan, L. (2010). A Culture of Trust Threatens Security and Privacy in Qatar. IEEE International Conference on Computer and Information Technology, 991-995.

Arnaud, B. (2018, September 25). eu-startups: The 10 most common reasons why startups fail. Retrieved from eu-startups: https://www.eu-startups.com/2018/09/the-10-mostcommon-reasons-why-startups-fail/ 
Belkhamza, Z., \& Wafa, S. (2014). The role of uncertainty avoidance on E-commerce acceptance across cultures. International Business Research, 7(5), 166.

Brain Station 23. (2019, September 18). Brain Station 23: E-Commerce Business Scenario in Bangaldesh. Retrieved from Brain Station 23: https://brainstation-23.com/ecommerce-business-scenario-in-bangladesh-2006-to-2018/

Changchit, T., Garofolo, J., \& Gonzalez, J. (2009). A cultural study of e-commerce trust: Hispanic versus Anglo. Journal of Information Science and Technology, 6(4), 30-34.

Chen, Y. H., Wu, J. J., \& Chung, Y. S. (2008). Cultural impact on trust: A comparison of virtual communities in China, Hong Kong, and Taiwan. Journal of Global Information Technology Management, 11(1), 28-48.

Cyr, D., \& Fraser, S. (2004). Localization of Web Design: An Empirical Comparison of German, Japanese, and U.S. Website Characteristics. Journal of the American Society of Information Science and Technology, 55, 1199-1208.

Dan, C. (2014). Electronic commerce: State-of-the-art. American Journal of Intelligent Systems, 4(4), 135-141.

Dhaka Tribune 1. (2019, August 20). Dhaka Tribune - Business. Retrieved from Dhaka Tribune: https://www.dhakatribune.com/business/2018/05/08/alibaba-buys-darazrocket-internet/

Dhaka Tribune 2. (2019, August 17). Dhaka Tribune - Business. Retrieved from Dhaka Tribune: https://www.dhakatribune.com/business/2018/09/08/walmart-and-amazonto-start-operating-in-bangladesh-in-2020

E-Commerce Association of Bangladesh. (2016, August 20). e-Cab - WP Content. Retrieved from e-Cab: http://e-cab.net/wp-content/uploads/2016/08/ECommerce_Policy_Framework_for_Bangladesh7.pdf

e-Commerce Association of Bangladesh. (2019, September 8). e-Commerce Association of Bangladesh - Bangladesh e-Commerce sector. Retrieved from e-Commerce Association of Bangladesh: http://e-cab.net/resource-center/bangladesh-e-commercesector/

Flood, M. (2014). Humanism and culture. Endorsed Transactions on Scalable Information Systems, 5, 2032-9407.

IDLC. (2018, August). E-Commerce of Bangaldesh: Shaping the future of shopping. IDLC Monthly Business Review, pp. 14(8), 6-13.

Imran, F. (2019, September 14). Techinasia - Bangladesh's startup scene may seem quiet, but not for long. Retrieved from Techinasia: https://www.techinasia.com/talk/bangladeshstartup-scene-quiet-not-for-long

Jarvenpaa, S. L., Tractinsky, N., \& Vitale, M. (2000). Consumer trust in an Internet store. Information Technology and Management, 1(1/2), 45-71. 
Lance, C. E., Butts, M. M., \& Michels, L. C. (2006). The Sources of Four Commonly Reported Cutoff Criteria. Organizational Research Methods, 9(2), 202-220.

Lauer, T. W., \& Deng, X. (2007). Building online trust through privacy practices. International Journal of Information Security, 6(5), 323-331.

Lin, A. C. (2015). Facilitating cultural and creative industries to engage the Internet era: A new e-commerce strategic framework. American Journal of Economics, 5(5), 534-539.

Manchanda, P. (2006). The Effect of Banner Advertising on Internet Purchasing. American Marketing Association, 43(1), 98-108.

McGowan, E. (2018, March 1). Startups.com: What Is a Startup Company, Anyway? Retrieved from Startups.com: https://www.startups.com/library/expert-advice/what-is-a-startupcompany

Mohiuddin, M. (2014). Overview the E-Commerce in Bangladesh. IOSR Journal of Business and Management (IOSR-JBM), 16 (7), 01-06.

New Age. (2018, July 17). New Age - Business. Retrieved from New Age: http://www.newagebd.net/article/46193/cabinet-approves-e-commerce-policy

New Age. (2019, September 17). New Age - Business. Retrieved from New Age: http://www.newagebd.net/article/28655/bangladesh-e-commerce-sector-to-grow-totk-900cr-this-year-report

Nunnally, J. C. (1978). Psychometric theory - 2nd Ed. New York: McGraw-Hill.

Nunnally, J. C., \& Bernstein, I. H. (1994). The Assessment of Reliability. Psychometric Theory, 3, 248-292.

Park, J., Gunn, F., \& Han, S. L. (2012). Multidimensional trust building in e-retailing: Crosscultural differences in trust formation and implications for perceived risk. Journal of Retailing and Consumer Services, 19(3), 304-312.

Ratnasingam, P. (2005). E-commerce relationships: The impact of trust on relationship continuity. International Journal of Commerce and Management, 15(1), 1-16.

Robehmed, N. (2013, Dec 16). Forbes: What Is A Startup? Retrieved from Forbes: https://www.forbes.com/sites/natalierobehmed/2013/12/16/what-is-astartup/\#7095026a4044

Rowley, J. (2001). Remodeling Marketing Communications in an Internet Environment, Internet Research. Electronic Net- working Applications and Policy, 11(3), 203-12.

Sialaa, H., O'Keefeb, R. M., \& Hone, K. S. (2000). The impact of religious affiliation on trust in the context of electronic commerce. Interacting with Computers, 16 (1), 7-27.

Simon, S. J. (2000). The impact of culture and gender on web sites: an empirical study. $A C M$ SIGMIS Database: the DATABASE for Advances in Information Systems, 32(1), 18-37. 
Singh, N., Kumar, V., \& Baack, D. (2005). Adaptation of Cultural Content: Evidence from B2C E-commerce Firms. European Journal of Marketing, 39, 71-86.

Singh, N., Zhao, H., \& Hu, X. (2012). Analyzing the Cultural Content of Web Sites: A CrossNational Comparison of China, India, Japan, and US. International Marketing Review, $22,129-145$.

Skok, D. (2019, September 17). For Entrepreneurs: 5 Reasons Startups Fail. Retrieved from For Entrepreneurs: https://www.forentrepreneurs.com/why-startups-fail/

Smith, A. D. (2004). Cybercriminal impacts on online business and consumer confidence. Online Information Review, 28(3), 224-234.

Sun, T. (2010). The roles of trust and experience in consumer confidence in conducting ecommerce: A cross-cultural comparison between France and Germany. International Journal of Consumer Studies, 35(3), 330 - 337.

The Daily Star. (2018, July 30). The Daily Star - Tech Happening. Retrieved from The Daily Star: https://www.thedailystar.net/bytes/our-digital-commerce-policy-nutshell1613056

Toru Institute of Inclusive Innovation. (2019, September 18). Toru Institute of Inclusive Innovation: UNDERSTANDING THE BANGLADESHI STARTUP ECOSYSTEM AND YOUR STARTUP'S ROLE IN IT. Retrieved September 18, 2019, from Toru Institute of Inclusive Innovation: http://toruinstitute.com/understanding-the-bangladeshi-startupecosystem/

Trochim, W. M., \& Donnelly, J. P. (2006). The Research Methods Knowledge Base. Cincinnati, $\mathrm{OH}$ : Atomic Dog.

Wang, H., Zhang, Y., \& Cao, J. (2009). Effective collaboration with information sharing in virtual universities. IEEE Trsig ansactions on Knowledge and Data Engineering, 21(6), 840-853.

Yohn, D. L. (2019, May 1). Forbes: Why Startups Fail. Retrieved from Forbes: https://www.forbes.com/sites/deniselyohn/2019/05/01/why-start-upsfail/\#11fae0c28a5d 


\title{
APPENDICES
}

\section{Survey Questionnaire for Research Report}

\section{Demographics:-}

1. Name:Contact No.:-

2. Gender: - $\square$ Male

\author{
$\square$ Female
}

3. Age: -

$\square$ Below 18 yrs. $\square 18-22$ yrs. $\square 23-26$ yrs. $\square 27-34$ yrs. $\square 35$ yrs. above

4. Education: -
$\square$ Graduate
$\square$ Post Graduate
$\square$ Others

5. Occupation:

$\square$ Student $\quad \square$ Service $\square$ Business $\quad \square$ Housewife $\square$ others

6. What types of products/services do you buy online:-
$\square$ Event tickets
$\square$ Clothes
$\square$ Consumer electronics
$\square$ Hotel/Travel booking
$\square$ Groceries
$\square$ Books
$\square$ other

For each of the following question below, please response by putting a tic mark beside the statement. Where 1= Strongly Disagree; 2= Disagree; 3=Neutral; 4=Agree and 5=Strongly Agree

\begin{tabular}{|c|c|c|c|c|c|c|}
\hline Sl.No & Question & 1 & 2 & 3 & 4 & 5 \\
\hline 1. & I prefer online shopping for cheaper price & & & & & \\
\hline 2. & I prefer online shopping limited edition products & & & & & \\
\hline 3. & $\begin{array}{l}\text { I prefer online shopping because visiting shops is exhausting to } \\
\text { me }\end{array}$ & & & & & \\
\hline 4. & I prefer online shopping because variety of product & & & & & \\
\hline 5. & I prefer online shopping to trying something new & & & & & \\
\hline 6. & $\begin{array}{l}\text { I prefer online because good after sales service affect my } \\
\text { willingness to repeat purchase }\end{array}$ & & & & & \\
\hline 7. & I have multiple payment option & & & & & \\
\hline 8. & I prefer Bangladeshi E-commerce website over international & & & & & \\
\hline 9. & I prefer colour, style, picture of the E-commerce site & & & & & \\
\hline 10 . & I prefer content of site in Bangla language & & & & & \\
\hline 11. & I prefer site to have multi-language option & & & & & \\
\hline 12. & I feel safe for my privacy \& security on E-commerce site & & & & & \\
\hline 13. & I'm aware of change privacy setting of E-commerce site & & & & & \\
\hline 14. & I receive what I order from the site & & & & & \\
\hline 15. & I feel E-commerce site are likely to care for my personal data & & & & & \\
\hline 16. & Secure and reliable payment system & & & & & \\
\hline 17. & E-commerce site always keep promises and commitments & & & & & \\
\hline
\end{tabular}

\section{Please write down the name of the site often visit}

1.

2.

3. 